OPEN ACCESS

Edited by:

Herui Wang,

National Cancer Institute (NCl),

United States

Reviewed by:

Alireza Mansouri,

Pennsylvania State University (PSU),

United States

Dusten Unruh,

Northwestern Medicine, United States

${ }^{*}$ Correspondence:

Alexis Palpan Flores

alexispalpan@hotmail.com

Maria Luisa Gandía González

marisagg4@hotmail.com

Specialty section:

This article was submitted to Neuro-Oncology and Neurosurgical

Oncology,

a section of the journa

Frontiers in Oncology

Received: 16 May 2020

Accepted: 28 July 2020

Published: 02 September 2020

Citation:

Palpan Flores A, Vivancos Sanchez C,

Roda JM, Cerdán S, Barrios AJ,

Utrilla C, Royo $A$ and Gandía

González ML (2020) Assessment of

Pre-operative Measurements of Tumor

Size by MRI Methods as Survival

Predictors in Wild Type IDH

Glioblastoma. Front. Oncol. 10:1662.

doi: 10.3389/fonc.2020.01662

\section{Assessment of Pre-operative Measurements of Tumor Size by MRI Methods as Survival Predictors in Wild Type IDH Glioblastoma}

\author{
Alexis Palpan Flores ${ }^{1 *}$, Catalina Vivancos Sanchez ${ }^{1}$, José M. Roda ${ }^{1}$, Sebastian Cerdán ${ }^{2}$, \\ Andres Javier Barrios ${ }^{3}$, Cristina Utrilla ${ }^{3}$, Aranzazu Royo ${ }^{3}$ and \\ Maria Luisa Gandía González ${ }^{1 *}$
}

${ }^{1}$ Department of Neurosurgery, University Hospital La Paz, Madrid, Spain, ${ }^{2}$ Institute of Biomedical Research "Alberto Sols" CSIC/UAM, Madrid, Spain, ${ }^{3}$ Department of Neuroradiology, University Hospital La Paz, Madrid, Spain

Objective: We evaluate the performance of three MRI methods to determine non-invasively tumor size, as overall survival (OS) and Progression Free Survival (PFS) predictors, in a cohort of wild type, IDH negative, glioblastoma patients. Investigated protocols included bidimensional (2D) diameter measurements, and three-dimensional (3D) estimations by the ellipsoid or semi-automatic segmentation methods.

Methods: We investigated OS in a cohort of 44 patients diagnosed with wild type IDH glioblastoma (58.2 \pm 11.4 years, 1.9/1 male/female) treated with neurosurgical resection followed by adjuvant chemo and radiotherapy. Pre-operative MRI images were evaluated to determine tumor mass area and volume, gadolinium enhancement volume, necrosis volume, and FLAIR-T 2 hyper-intensity area and volume. We implemented then multivariate Cox statistical analysis to select optimal predictors for OS and PFS.

Results: Median OS was 16 months (1-42 months), ranging from $9 \pm 2.4$ months in patients over 65 years, to $18 \pm 1.6$ months in younger ones. Patients with tumors carrying $0^{6}$-methylguanin-DNA-methyltransferase (MGMT) methylation survived $30 \pm 5.2$ vs. 13 \pm 2.5 months in non-methylated. Our study evidenced high and positive correlations among the results of the three methods to determine tumor size. FLAIR- $T_{2}$ hyper-intensity areas (2D) and volumes (3D) were also similar as determined by the three methods. Cox proportional hazards analysis with the $2 \mathrm{D}$ and $3 \mathrm{D}$ methods indicated that OS was associated to age $\geq 65$ years (HR 2.70, 2.94, and 3.16), MGMT methylation (HR 2.98, 3.07, and 2.90), and FLAIR-T $2 \geq 2,000 \mathrm{~mm}^{2}$ or $\geq 60 \mathrm{~cm}^{3}$ (HR 4.16, 3.93, and 3.72), respectively. Other variables including necrosis, tumor mass, necrosis/tumor ratio, and FLAIR/tumor ratio were not significantly correlated with OS.

Conclusion: Our results reveal a high correlation among measurements of tumor size performed with the three methods. Pre-operative FLAIR-T $T_{2}$ hyperintensity area and volumes provided, independently of the measurement method, the optimal neuroimaging features predicting OS in primary glioblastoma patients, followed by age $\geq 65$ years and MGMT methylation.

Keywords: glioblastoma, overall survival, progression free survival, IDH mutation, tumor volumetry, linear method, semi-automatic segmentation method, ellipsoid method 


\section{INTRODUCTION}

Glioblastomas are the most aggressive and frequent primary tumors of the central nervous system in adult populations, with an approximate incidence of 3-5/100,000 people $(1,2)$. Overall Survival (OS) predictions around 12-18 months are normally expected, remaining poor despite surgical, and adjuvant chemo- and radio-therapy treatments $(3,4)$. Glioblastomas are currently classified in primary or secondary subtypes, reflecting either a "de novo" origin without evidence of any preceding lesion or, a "progression from a lower grade astrocytoma," respectively (5). Both subtypes have very different OS profiles, with longer survival estimates for the secondary. The molecular signature discriminating between primary (IDH wild type), or secondary subtypes, is the absence or presence, of the isocitrate dehydrogenase (IDH) mutation (5-7), respectively. Methylation of the O6 methylguanine DNA Methyltransferase (MGMT) promoter represents the next molecular feature in prognostic relevance, predicting a better response to alkylating agents like temozolamide (TMZ), during adjuvant chemotherapy $(8,9)$.

Both, clinical and neuroimaging variables, have been repeatedly recommended as prognostic factors $(10,11)$. More specifically, non-invasive measurements of the tumor size have played a controversial role in OS and Progression Free Survival (PFS) predictions of glioblastoma patients (12-19). Briefly, Magnetic Resonance Imaging (MRI) measurements of twodimensional (2D) diameters of the tumor through the imaging plane were recommended initially by Macdonald et al. (20), and later incorporated by the Response Assessment Neuro-Oncology (RANO) working group (21), as criteria of response to therapy. However, the efficacy of the $2 \mathrm{D}$ protocol remains currently under debate, particularly, in morphologically irregular tumors (22-24). Almost in parallel, the 3D ellipsoid method, calculating the tumor volume $(25,26)$ and using three orthogonal diameters, was implemented for different tumors, including glioblastoma. However, the irregular shape of most tumors continued to limit accurate volume determinations using this approach $(24,27)$. More recently, advanced 3D image-processing software packages using semi-automatic segmentation algorithms have become available, providing more accurate estimations of tumor volumes, with the ability to measure irregular tumor shapes and their compartments $(22,28)$. Nevertheless, a main question arises on whether this increased accuracy in the volume measurement results in any benefit in terms of prognosis, as compared to the other two, simpler to implement, methods (23).

Notably, OS and PFS in glioblastomas have been previously associated to various compartmental tumor volumes including: the volume of necrosis (12-14), the volume of contrastenhancing tumor (11), the volume of FLAIR- $T_{2}$ hyperintensity $(13-18)$, or the tumor/necrosis volume ratio $(13,19)$.

\footnotetext{
Abbreviations: CI, Confidence Interval; d, days; EOR, Extent of resection; ET, Enhancing tumor; FLAIR, Fluid-attenuation inversion recovery; FTR, FLAIR-T 2 /Tumor mass ratio; HR, Hazard ratio (Cox method); IDH, Isocitrate dehydrogenase; m, months; MGMT, $\mathrm{O}^{6}$-methylguanin-DNA-methyltransferase; MRI, Magnetic resonance imaging; NTR, Necrosis/Tumor mass ratio; PFS, Progression-free survival; ROI, region of interest; RTV, Residual tumor volume; TM, Tumor mass; TMZ, Temozolamide; TN, Tumoral necrosis; y, years.
}

Unfortunately, results and conclusions from many of these studies remain contradictory. Discrepancies may originate, at least partially, from the diversity of volumetric techniques implemented and, in some cases, from incomplete morphological or molecular characterizations of the tumors investigated. Together, these limitations result in a plethora of uncertainties, preventing more accurate predictions $(6,13)$. On these grounds, assessment of the influence of the different methods of presurgical tumor volume determination, their relationship with the underlying clinical and genetic biomarkers, or even with the efficacy of the neurosurgical resections, entail vital relevance to improve the accuracy of current OS and PFS predictions.

On these grounds, we aimed here to assess the influence of different methods of determination of the tumor size, tumor compartments, genetic profile, and some relevant clinical and neurosurgical variables, in the prediction of OS and PFS in primary glioblastomas. To this end, we investigated OS and PFS in a consecutive cohort of patients with primary IDH wild-type glioblastomas, selected as candidates for neurosurgical resection, followed by adjuvant chemo- and radiotherapy. Then, we compared measurements of the tumoral size and its compartments by the $2 \mathrm{D}$ diameter, the $3 \mathrm{D}$ ellipsoid, and the 3D semi-automatic (Smartbrush ${ }^{\circledR}$ software by Brainlab AG) methods, and correlated them with OS and PFS, considering also the profile of IDH and MGMT mutations, clinical variables as anatomical location or eloquence, and the extension of resection. We found high correlations among measurements of tumoral size by the three methods, with pre-operative FLAIR-T 2 hyperintensity areas and volumes providing the optimal neuroimaging biomarker to predict OS in primary glioblastoma patients, together with age $\geq 65$ years and MGMT methylation.

\section{MATERIALS AND METHODS \\ Study Design}

Our study was conducted in the period 2015-2019, with the consecutive inclusion of adult patients with newly diagnosed IDH wild-type glioblastomas (Grade IV WHO), treated in the Neurosurgery Department of the University Hospital La Paz, Madrid, Spain (https://www.comunidad.madrid/hospital/ lapaz/). The protocol was approved by the institutional ethics committee, followed the rules of the Helsinki Declaration, and complied with the STROBE checklist (29).

All consecutive adult patients with suspected high-grade glioma, candidates for surgical resection were initially included. Thereafter, 44 patients were selected, with a definitive diagnosis of glioblastoma in the absence of IDH mutation. Inclusion criteria were:

i) Pre-operative MRI, at least $72 \mathrm{~h}$ after treatment with dexamethasone ( $4 \mathrm{mg}$, every $8 \mathrm{~h}$ ),

ii) Post-operative MRI, between 24 and $48 \mathrm{~h}$ after surgery, to assess the presence of tumor in contrast enhancement tissue $(30,31)$ and,

iii) Radiotherapy (2.0 grays Gy/day, 60 Gy total) and TMZ (75 $\mathrm{mg} / \mathrm{m}^{2}$ oral daily) according to Stupp (32), followed by adjuvant TMZ (150-200 mg/m² oral for 5 days during 


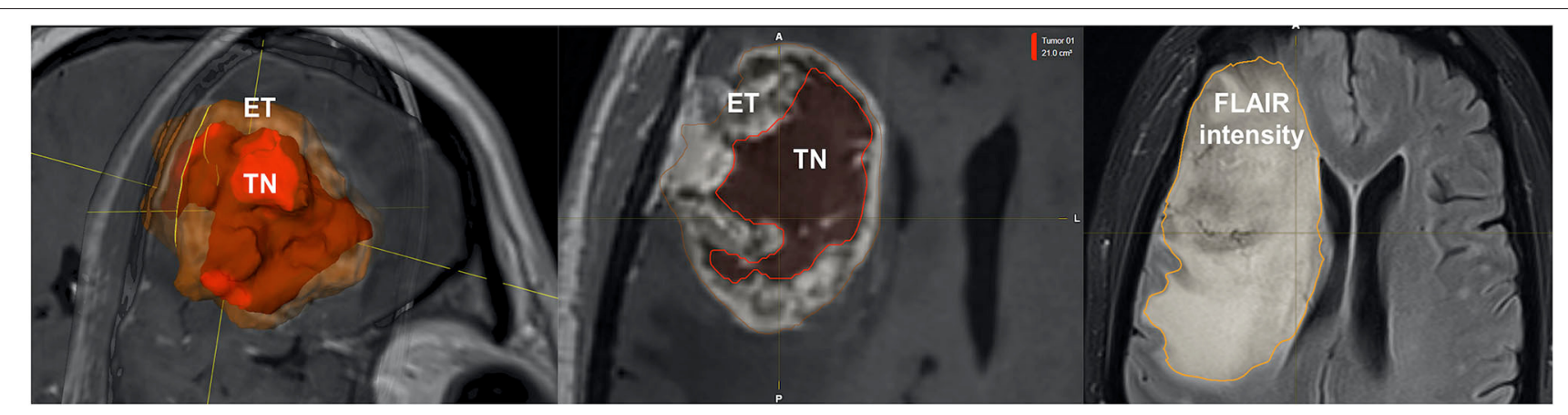

FIGURE 1 | Representative volumetric parameters calculated by the semi-automatic method. Similar compartments were measured by the 2D and, 3D ellipsoid methods. Left: Enhancing tumor (ET), Center: Tumor necrosis (TN), Right: Fluid-attenuation inversion recovery (FLAIR intensity).

each 28-day cycle) with 6-12 cycles depending on the therapeutic response.

The exclusion criteria were patients who could not be offered the standard treatment (resective surgery followed by chemoradiotherapy) because of very high surgical risk, or also those who refused surgical or chemo- and/or-radiotherapy treatments.

\section{MRI}

Magnetic Resonance Imaging (MRI) was performed preoperatively in a 3 Tesla magnet, (MAGNETOM Skyra, Siemens, Erlangen/Germany) and postoperatively at 1.5 Tesla (MAGNETOM Avanto, Siemens, Erlangen/Germany).

Pre-operative MRI included: Sagittal $3 \mathrm{D}-\mathrm{T}_{1 \mathrm{w}}-\mathrm{SPACE}$ (TR: $650 \mathrm{~ms}$, TE: $11 \mathrm{~ms}$, and $1 \mathrm{~mm}$ isotropic resolution) before and after gadolinium (Dotarem ${ }^{\circledR} 0.2 \mathrm{~mL} / \mathrm{kg}$ IV bolus infused at rate of $2 \mathrm{~mL} / \mathrm{s}$ ) administration, Axial and Coronal 2D-T $\mathrm{T}_{\mathrm{w}}-\mathrm{FSE}$ ( $\mathrm{TR}=4,450 \mathrm{~ms}$, TE: $83 \mathrm{~ms}$, and slice thickness: $4 \mathrm{~mm}$ ), Axial 2D Fluid-Attenuation Inversion Recovery (FLAIR) (TR $=12,000 \mathrm{~ms}$, TE: $101 \mathrm{~ms}$, and TI: 2,760).

Post-operative MRI included: Sagittal $3 \mathrm{D}-\mathrm{T}_{1 \mathrm{w}}$-SPACE (TR: $600 \mathrm{~ms}$, TE: $8 \mathrm{~ms}$, and $1 \mathrm{~mm}$ isotropic resolution), Axial and Coronal 2D-T $\mathrm{T}_{2 \mathrm{w}}-\mathrm{FSE}$ (TR: 4,000 ms, TE: $81 \mathrm{~ms}$, and slice thickness: $5 \mathrm{~mm}$ ), Axial 2D FLAIR (TR $=9,000 \mathrm{~ms}$, TE: $92 \mathrm{~ms}$, and TI: 2,500). Sagittal $3 \mathrm{D}-\mathrm{T}_{1 \mathrm{w}}-\mathrm{SPACE}$ with contrast (TR: $450 \mathrm{~ms}$, TE: $11 \mathrm{~ms}$, and $1 \mathrm{~mm}$ isotropic resolution).

\section{Tumor Size Analysis}

Quantitative measurements were performed by two neurosurgeons who jointly carried out the determinations. Representative pre-operative MRI measurements of tumor size measurements are illustrated in Figure 1, implementing either;

i) 2D diameters method: as the sum of the products of perpendicular diameters of all contrast-enhancing lesions in $\mathrm{T}_{1}$, as recommended by RANO (23) (Figure 2),

ii) Orthogonal ellipsoid method: as the product of the longest perpendicular diameters in axial (a), sagittal (b), and coronal (c) sections divided by two $(\mathrm{a} \times \mathrm{b} \times \mathrm{c} / 2)$, preferred to the formula $4 / 3$ pi $(a / 2 \times b / 2 \times c / 2)$ for its easier and more reliable implementation $(27,33)$ (Figure 3); and iii) Manually selecting the region of interest (ROI) using the Smartbrush tool of semi-automatic segmentation software (BrainLAB $^{\circledR}$, Munich Germany; Figure 4).

The following volumetric compartments, their definitions, and ratios were chosen, to be able to correlate with the OS estimates in previous studies (11-19):

a) Enhancing tumor (ET) in the $T_{1}$ sequence: As the tumor enhancement after gadolinium injection.

b) Tumoral necrosis (TN): as the region of enhancing tumor which does not show enhancement after gadolinium administration. Non-necrotic cystic lesions were excluded.

c) Tumor mass (TM): Sum of the enhancing tumor and necrosis.

d) Hyperintensity in FLAIR- $\mathrm{T}_{2}$ : as the region of hyper-intensity in FLAIR- $\mathrm{T}_{2}$ including the tumor mass and peritumoral area, including vasogenic edema and tumor infiltration.

e) Residual tumor volume (RTV): Volume of enhancement that results from the post-contrast and pre-contrast subtraction in the $\mathrm{T}_{1}$ sequence, reflecting the residual "enhancing tumor."

f) Extent of resection (EOR): as the result of: [(initial enhancing tumor) - (the remaining enhancing tumor after resection)]/(initial enhancing tumor) expressed as a percentage.

g) Necrosis/Tumor mass ratio (NTR).

h) FLAIR-T 2 /Tumor mass ratio (FTR).

\section{Immunohistochemistry and Genetic Assessment}

Anatomopathological analysis of biopsies obtained during neurosurgery included the immunohistochemical detection of the IDH (isocitrate dehydrogenase $\mathrm{R} 132 \mathrm{H}$ ) mutation. In negative cases, with high suspicion of IDH mutation no-R132H, a genetic study was performed by pyrosequencing (34). All cases underwent analysis of the methylation status of the $\mathrm{O}^{6}$ methylguanine-DNA methyltransferase (MGMT) promoter using the MethyLigh PCR reaction (35).

\section{Statistics}

Univariate statistical analyses included analysis of means, median and standard deviation. Bivariate analysis were 


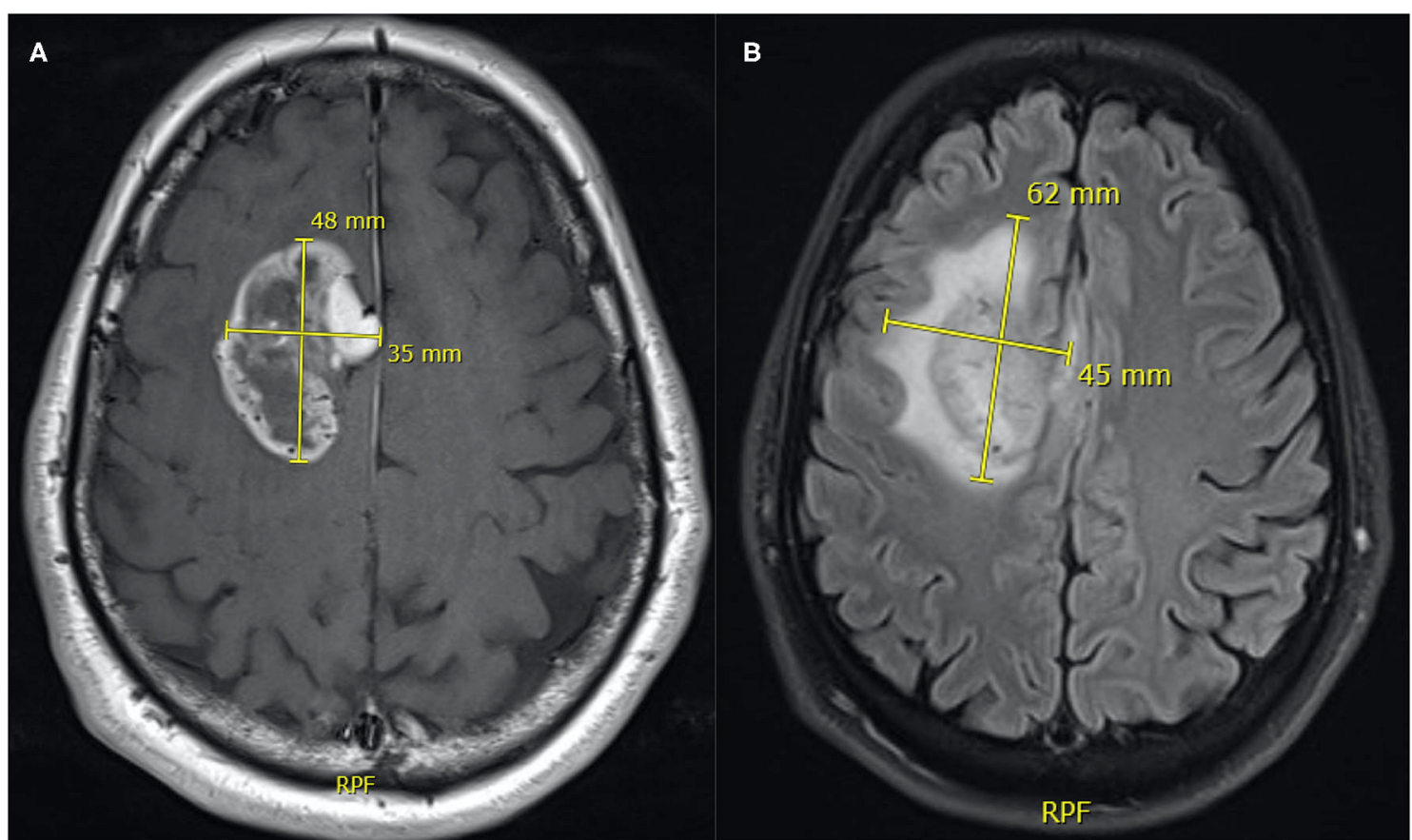

FIGURE 2 | Representative measurements of tumor size (A) and FLAIR- $T_{2}$ (B) area by the $2 \mathrm{D}$ orthogonal diameters method. The area of the tumor mass is the product of $48 \times 35 \mathrm{~mm}=1,680 \mathrm{~mm}^{2}$ and the FLAIR-T 2 area is $62 \times 45 \mathrm{~mm}=2,790 \mathrm{~mm}^{2}$.

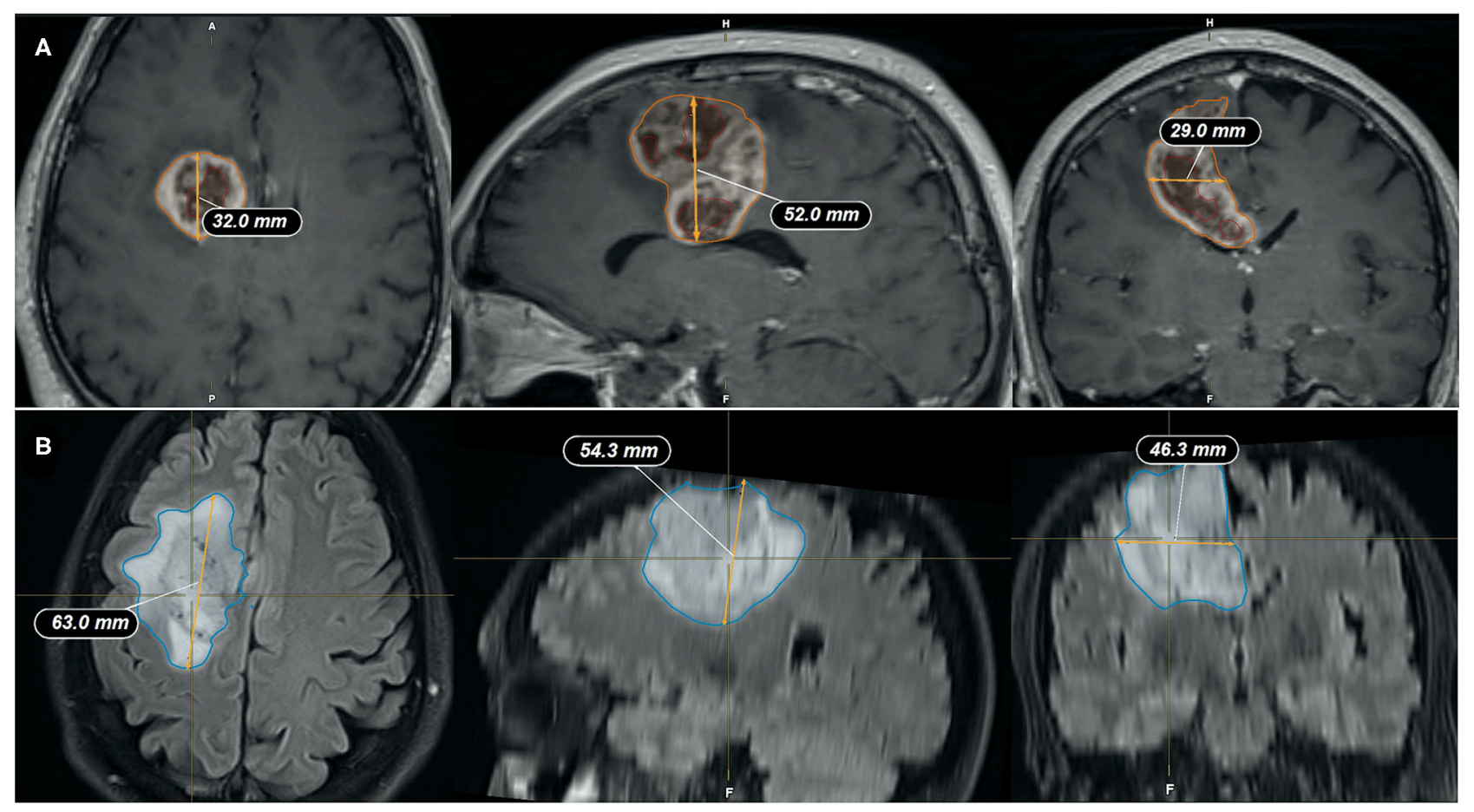

FIGURE 3 | Representative measurements of the tumor size by the ellipsoid method. (A) Tumor mass volume is: (32 $\times 52 \times 29 \mathrm{~mm}) / 2=24.13 \mathrm{~cm}^{3}$; (B) FLAIR-T volume is: $(63 \times 54.3 \times 46.3 \mathrm{~mm}) / 2=79.19 \mathrm{~cm}^{3}$. Coronal (left), Sagital (center), and Axial (right) slices through the tumor. 


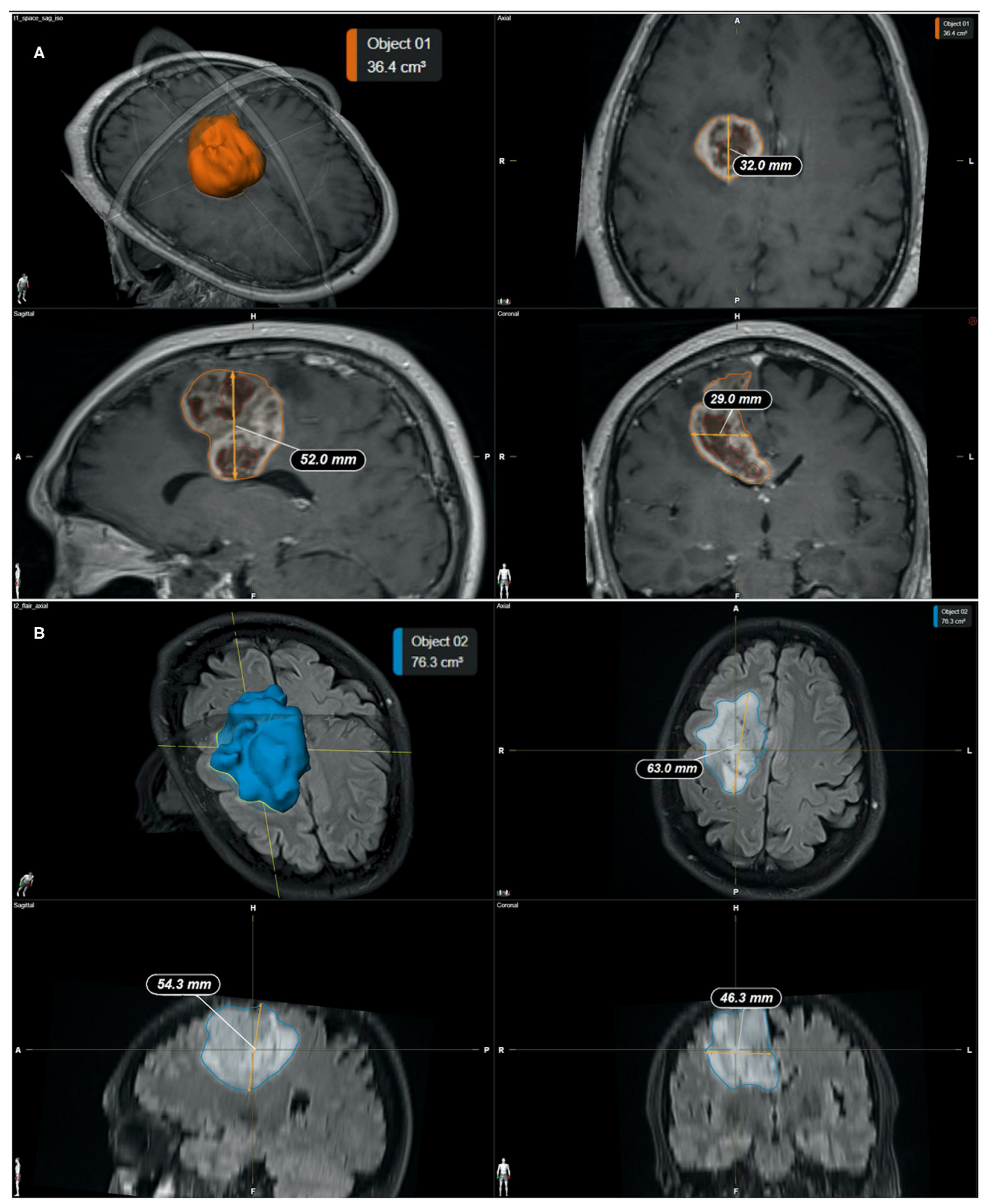

FIGURE 4 | (A) Representative measurements of the tumor mass by the semi-automatic method (SmartBrush software-BrainLAB ${ }^{\circledR}$ ). (A) Calculated tumor mass volume is $36.4 \mathrm{~cm}^{3}$; (B) Calculated FLAIR-T 2 volume is $76.3 \mathrm{~cm}^{3}$. Individual panels indicate; 3D reconstruction (top left), Coronal (top right), Sagital (bottom left), and Axial (bottom right) slices through the tumor, respectively. 
TABLE 1 | Clinical, genetic, neurosurgical, and chemotherapy variables of the patient cohort and associated overall survival, and progression free survivals.

\begin{tabular}{|c|c|c|}
\hline Parameter & & $n=44$ \\
\hline Age & Mean (years) $\pm S D$ (range) & $58.2 \pm 11.4(35-81)$ \\
\hline \multirow[t]{2}{*}{ Gender } & Male & 29 (65.9\%) \\
\hline & Female & $15(34.1 \%)$ \\
\hline Comorbidity $^{a}$ & & $26(59.1 \%)$ \\
\hline Karnofsky Scale & Median (range) & $90(70-100)$ \\
\hline \multirow[t]{2}{*}{ Hemisphere } & Right & $26(59.1 \%)$ \\
\hline & Left & $18(40.9 \%)$ \\
\hline \multirow[t]{3}{*}{ Eloquency ${ }^{b}$} & Not eloquent ratio & 10/44 (22.7\%) \\
\hline & Near-eloquent ratio & $30 / 44(68.2 \%)$ \\
\hline & Eloquent ratio & $4 / 44(9.1 \%)$ \\
\hline \multirow[t]{6}{*}{ Location } & Frontal & $13(29.5 \%)$ \\
\hline & Temporal & $11(25 \%)$ \\
\hline & Parietal & $11(25 \%)$ \\
\hline & Occipital & $9(20.5 \%)$ \\
\hline & Deep & $0(0 \%)$ \\
\hline & Multicentric & $4(9.1 \%)$ \\
\hline \multirow[t]{2}{*}{ MGMT status } & Methylated & $17(38.6 \%)$ \\
\hline & Non-methylated & 27 (61.4\%) \\
\hline IDH wild-type & & $100 \%$ \\
\hline Extent of Resection & \%, Median (Q1-Q3) & $95.9(89.03-100)$ \\
\hline Stupp protocolc & & $100 \%$ \\
\hline Chemotherapy with TMZ & Median of cycles (Q1-Q3) & $6(3-12)$ \\
\hline Second line of chemotherapy ${ }^{d}$ & & $10(22.7 \%)$ \\
\hline Progression free survival & Median (months), 95\% Cl & $7(5-9)$ \\
\hline Overall survival & Median (months), 95\% Cl & $16(11-19)$ \\
\hline
\end{tabular}

${ }^{a}$ Arterial hypertension, diabetes mellitus, and/or pulmonary, renal, cardiac, oncologic, or any severe disease, bloquency according to Sawaya et al. (36); TMZ, Temozolamide; MGMT, $\mathrm{O}^{6}$-methylguanin-DNA-methyltransferase; ' Stupp protocol, Radiotherapy (2.0 grays [Gy]/day; total dose, 60 Gy), and temozolomide (75 $\mathrm{mg} / \mathrm{m}^{2}$ orally daily) (32); 'Lomusitne or Fotemustine; Q1-Q3 first and third quartiles (interquartile range); Cl, confidence interval.

performed according of the type of variable; Pearson and Spearman's correlation coefficient to compare among volumetric and diameter measurements by three methods, MannWhitney $U$-test for volumes according to the state of MGMT methylation, with log-rank test used for time-event analyzes and survival analysis using the Kaplan-Meier method. Finally, the multivariate analysis was performed using Cox regression test to assess the independence of possible prognostic factors in overall and progression free survival for the three measurement techniques. The analysis was conducted using Microsoft Excel 2016 and the statistical package Stata version 14 (StataCorp LLC, Texas, USA) as implemented in a personal PC operating under the MacOS environment.

\section{RESULTS}

Table 1 summarizes the patient cohort and tumor characteristics of our study. A total of 44 patients met the inclusion criteria. Mean age was $58.15 \pm 11.36$ (range 35-81 years), with a
TABLE 2 | Tumor and compartment volumes as calculated by 2D diameter, ellipsoid, and semi-automatic segmentation methods.

\begin{tabular}{|c|c|c|}
\hline Method & Compartment & Value (units) \\
\hline \multirow[t]{3}{*}{ 2D diameter } & $\begin{array}{l}\text { Area of the tumor } \\
\text { mass }^{a}\end{array}$ & $1,203 \pm 911(80-3,720) \mathrm{mm}^{2}$ \\
\hline & $\begin{array}{l}\text { Area of } \\
\text { hyperintensity in } \\
\text { FLAIR-T }\end{array}$ & $3,210 \pm 1,422(780-5,795) \mathrm{mm}^{2}$ \\
\hline & $\begin{array}{l}\text { FLAIR-T } / \text { tumor } \\
\text { ratioc }^{c}\end{array}$ & $2.91 \pm 3.48(1.2-17.9)$ \\
\hline \multirow[t]{3}{*}{ 3D Ellipsoid } & Tumoral mass & $24.9 \pm 23.1(0.4-96.7) \mathrm{cm}^{3}$ \\
\hline & FLAIR-T 2 volume & $89.7 \pm 51.2(8.9-191) \mathrm{cm}^{3}$ \\
\hline & $\begin{array}{l}\text { FLAIR-T } / \text { /tumor } \\
\text { ratio }^{c}\end{array}$ & $4.14(2.6-7.15)$ \\
\hline \multirow[t]{6}{*}{ 3D semi-automatic } & $\begin{array}{l}\text { Enhancing tumorb } \\
(\mathrm{T} 1+\mathrm{Gd})\end{array}$ & $14.2 \pm 12.2(0.8-47) \mathrm{cm}^{3}$ \\
\hline & Necrosis $^{b}$ & $15.6 \pm 18.3(0-73) \mathrm{cm}^{3}$ \\
\hline & Tumoral mass & $29.8 \pm 26.9(1.1-120) \mathrm{cm}^{3}$ \\
\hline & FLAIR-T 2 volume & $95.7 \pm 55.2(6.7-202) \mathrm{cm}^{3}$ \\
\hline & $\begin{array}{l}\text { FLAIR-T } / \text { tumor } \\
\text { ratio }^{c}\end{array}$ & $3.39(2.32-5.5)$ \\
\hline & $\begin{array}{l}\text { Necrosis/tumor } \\
\text { ratio }^{\text {b,c }}\end{array}$ & $0.44(0.26-0.59)$ \\
\hline
\end{tabular}

Results are expressed as mean $\pm S D$ with range of measured values in parenthesis.

${ }^{a}$ Necrosis + enhancing tumor in $\mathrm{T} 1+\mathrm{Gd}$.

${ }^{b}$ Only measurable by Semi-automatic method.

${ }^{c} \mathrm{Q} 1$ and $Q 3$ indicate the first and third quartiles.

male/female ratio of 1.9/1, reflecting masculine predominance (2). The median of Karnofsky index (37) was 90 (range 70-100) with the frontal location most frequently found 13/44 (29.5\%) and the right/left distribution of $0.7 / 1$. The percentage tumors in eloquent and near-eloquent areas (36) were 9.1 and $68.2 \%$, respectively. Most frequent clinical presentations included; headache (40\%), cognitive deficit (31.1\%), and motor deficit (26.7\%). All patients were IDH negative and the percentage of the methylation of the MGMT promoter was 38.6\%. Six cycles of chemotherapy each 28 days with TMZ was completed in $63.6 \%$ of patients. Re-operation was performed in $15.6 \%$ of them. A second line of chemotherapy was administered in $28.9 \%$, with Fotemustine $^{\circledR}(22.7 \%)$ and Lomustine ${ }^{\circledR}(6.8 \%)$ as the most used drugs. Median percentage of tumor resection was $95.9 \%$ (range 62.3-100\%).

\section{Tumor Size and Compartmental Correlation Analysis: Diameters, Ellipsoid, and Semi-automatic Methods}

Table 2 summarizes measurements of different tumor compartmental areas and volumes with the three methods investigated, while Figure 5 provides the correlations within them. Most of the compartmental volumes determined by the 3D ellipsoid and automatic segmentation methods were similar, revealing consistency. Similarly, using the sum of the products of major perpendicular diameters, the mean of tumor area had a high correlation with the tumor mass volume 

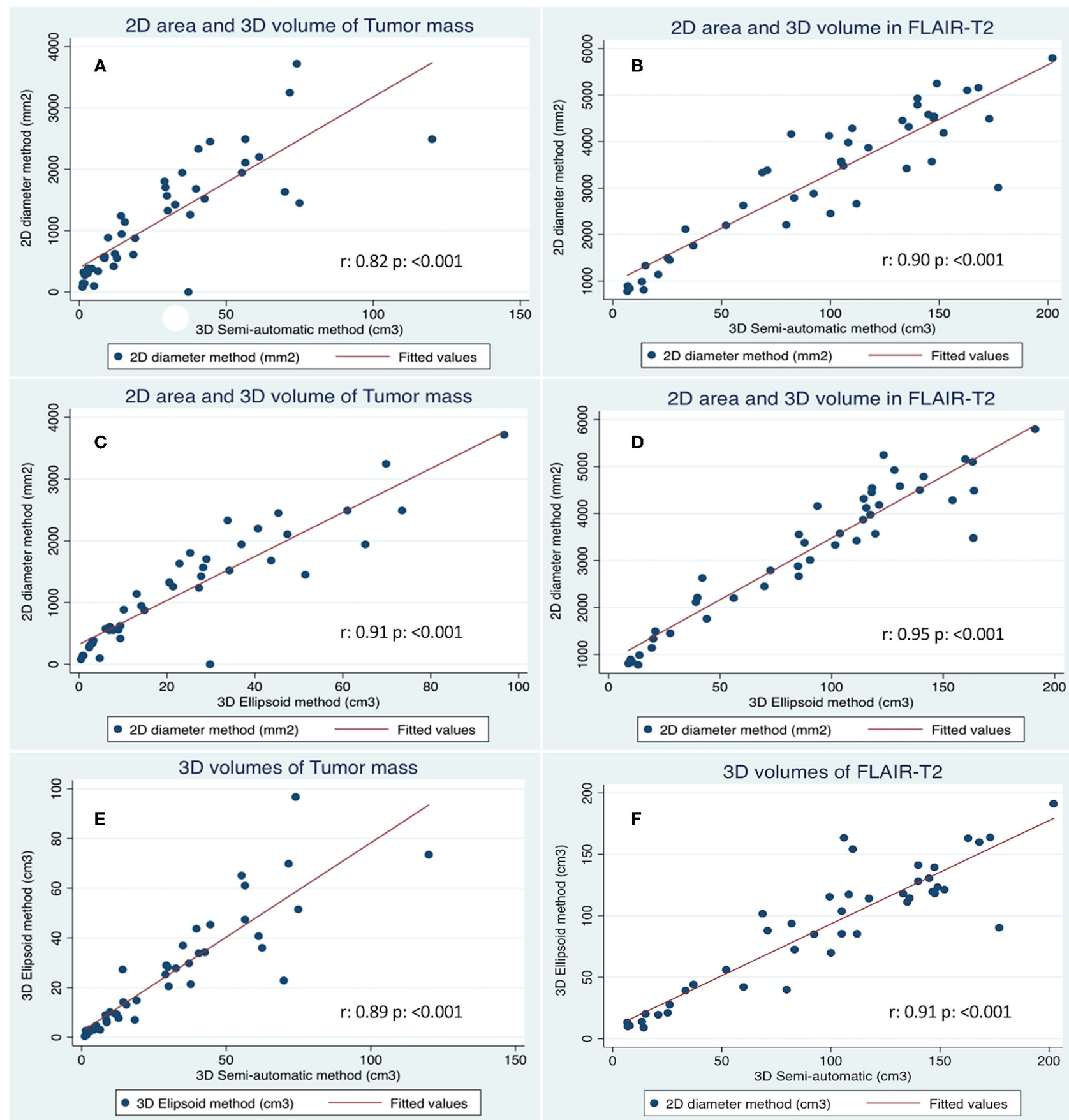

FIGURE 5 | Correlation of tumor size measurements as performed with the three methods. (A) Tumor mass calculated with the 2D diameter vs. 3D Semi-automatic methods. (B) FLAIR-T 2 area and volume calculated with 2D diameter vs. 3D semi-automatic methods. (C) Tumor mass calculated with the 2D diameter vs. 3D Ellipsoid method. (D) FLAIR-T 2 area and volume calculated with 2D diameter vs. 3D Ellipsoid method. (E) Tumor mass calculated with the 3D Ellipsoid vs. 3D Semi-automatic method. (F) FLAIR-T 2 volumes calculated with 3D Ellipsoid vs. 3D Semi-automatic methods.

measured by the ellipsoid $(r=0.91, p<0.001)$, and semiautomatic segmentation $(r=0.82, p<0.001)$ methods. The mean FLAIR-T 2 area also highly correlated with the FLAIR-T 2 volume by the ellipsoid method ( $r=0.95, p<0.001)$, and the semi-automatic segmentation $(r=0.90, p<0.001)$ methods
(Figure 5). The mean of the enhancing tumor and of the necrosis volumes were only assessed by the semi-automatic segmentation method, since the irregular morphology hampered the use of the 2D diameter method and the ellipsoid formula. 
We found a high correlation between the means of the tumor mass volume (Figure 5E, $r=0.89, p<0.001$ ) and between the means of the FLAIR-T 2 volumes (Figure 5F, $r=$ $0.91, p<0.001)$ by both methods. The correlation between the means of the FLAIR-T 2 /tumor ratio were not as high as the primary measurements, between the $2 \mathrm{D}$ diameter and the ellipsoid method was $(r=0.69, p<0.001)$, between ellipsoid and semi-automatic methods was $(r=0.84, p<0.001)$ and
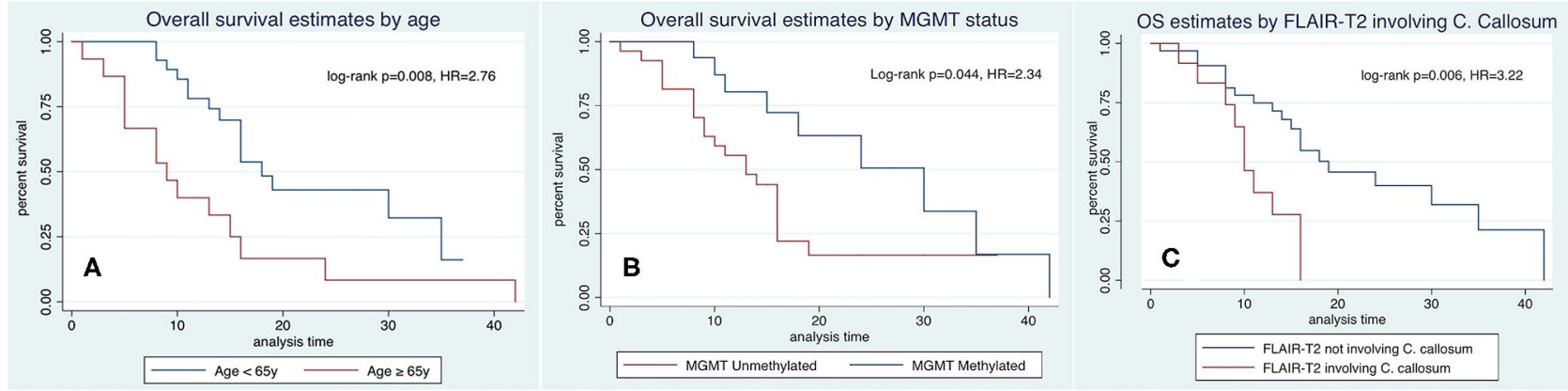

FIGURE 6 | Kaplan-Meyer analysis of OS as predicted by age (A), methylation status of the MGMT promoter (B), and hyperintensity in FLAIR-T 2 involving the corpus callosum (C).
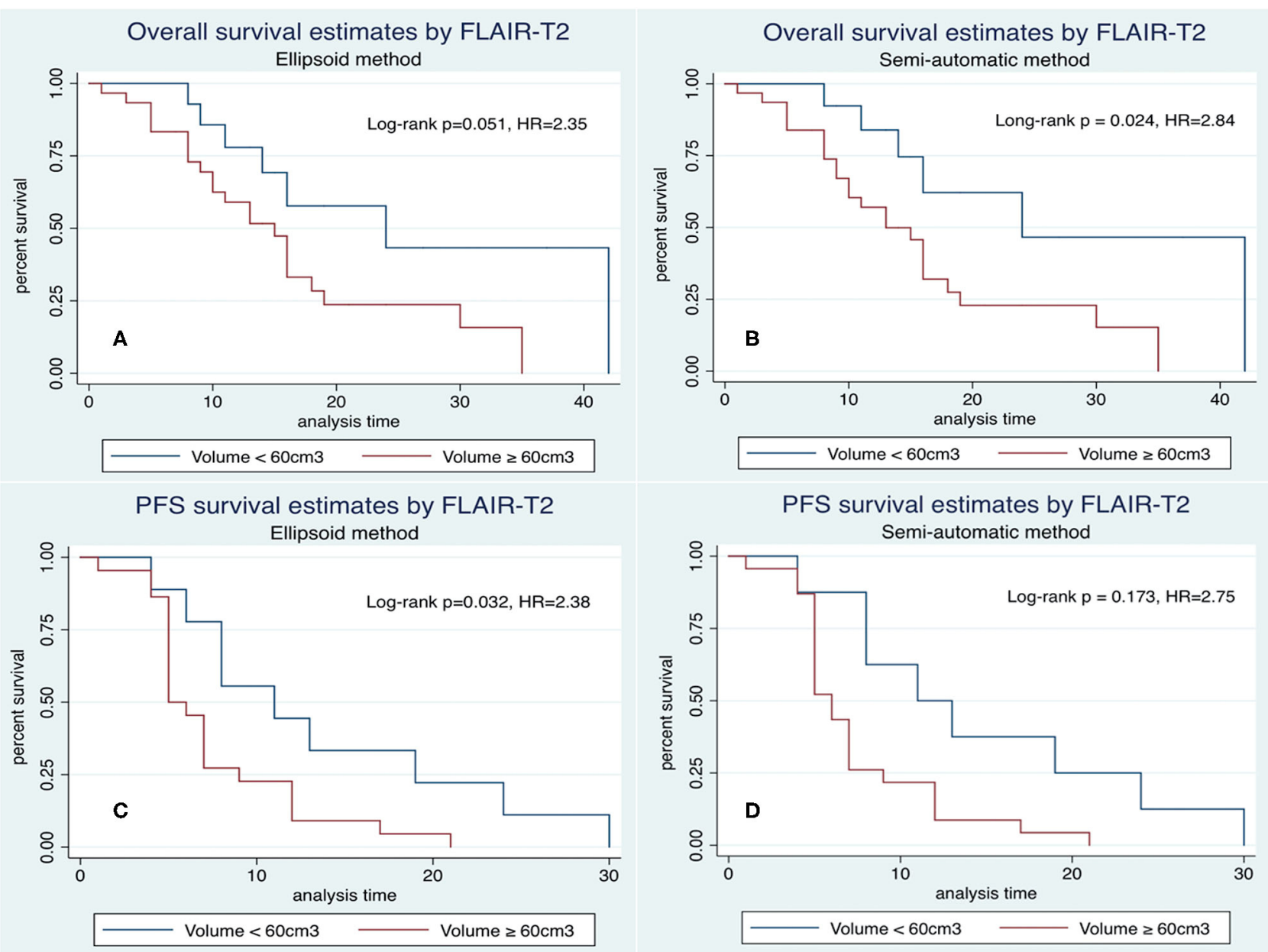

FIGURE 7 | Kaplan-Meier representation of overall survival (A,B) and progression-free survival (C,D) related to pre-operative FLAIR-T 2 volume $\geq 60 \mathrm{~cm}^{3}$ by $3 D$ ellipsoid (A-C) and semi-automatic segmentation (B-D) methods. 
between 2D diameter and semi-automatic method was $(r=0.56$, $p<0.001)$. The necrosis/tumor ratio could only be obtained by the semi-automatic method and therefore could not be correlated with other methods.

\section{Survival Analysis}

Figure 6 illustrates Kaplan-Meier profiles of OS depending on the age of the patients and methylation status of the tumors. Median OS of the investigated cohort was $16 \pm 9.1$ months (range 1-42 months). Gender, Karnofsky status, location of the tumor, eloquence and extent of tumor resection, had no impact on OS, although tumors with a extent of resection higher than $98 \%$ showed a tendency to greater survival, almost reaching statistical significance ( $18 \pm 2.6$ vs. $14 \pm 4.2$ months, $p=0.497)$. The following features merit further comments.

Age. Elderly were associated with a higher mortality in the bivariate analysis, being $18 \pm 1.6$ months in patients $<65$ years, and $9 \pm 2.4$ months in patients $\geq 65$ years (Figure 6A, HR 2.76, $p=0.008)$.

MGMT methylation was associated with longer OS, $30 \pm 5.2$ months in methylated vs. $13 \pm 2.5$ months in non-methylated (Figure 6B, HR $=2.34, p=0.044$ ). Necrosis, tumor mass, and FLAIR- $\mathrm{T}_{2}$ volumes in non-methylated MGMT tumors were larger than in methylated MGMT tumors: 18.7 vs. $10.7 \mathrm{~cm}^{3}$, 33.9 vs. $23.3 \mathrm{~cm}^{3}$, and 104.3 vs. $82.1 \mathrm{~cm}^{3}$, respectively, without statistical significance (Mann-Whitney $U$-test $p=0.161,0.204$, and 0.195 , respectively).

Hyperintensity in FLAIR-T $T_{2}$ involving the corpus callosum had a significant impact in OS, $10 \pm 1.08$ months when there was involvement of the corpus callosum vs. $19 \pm 3.7$ months when there was no involvement of the corpus callosum (Figure 6C, HR $=3.22, p=0.006$ ).

Gadolinium enhancing tumor, necrosis, and the tumor mass volumes calculated by the $3 \mathrm{D}$ ellipsoid and $3 \mathrm{D}$ semi-automatic methods did not have any impact on OS and PFS, and the tumor mass area, calculated with the $2 \mathrm{D}$ diameter method, was not associated with OS or PFS either.

Figure 7 and Tables 3-5, summarizes Kaplan-Meier tests of $\mathrm{OS}$ and PFS with pre-operative FLAIR-T 2 volume measurements by the $3 \mathrm{D}$ ellipsoid, and semiautomatic segmentation methods, respectively.

TABLE 3 | Multivariate Cox Regression analysis with tumor size as determined by the $2 \mathrm{D}$ diameter method.

\begin{tabular}{|c|c|c|c|c|c|c|}
\hline Variable & $\begin{array}{c}\text { Unadjusted } \\
\text { HR }\end{array}$ & $95 \% \mathrm{Cl}$ & $p$-value & $\begin{array}{c}\text { Adjusted } \\
\text { HR }\end{array}$ & $95 \% \mathrm{Cl}$ & $p$-value \\
\hline $\begin{array}{l}\text { Age } \geq 65 \\
\text { years }\end{array}$ & 2.76 & $1.30-5.84$ & 0.008 & 2.85 & $1.26-6.41$ & 0.011 \\
\hline $\begin{array}{l}\text { MGMT } \\
\text { Unmethylated }\end{array}$ & 2.34 & $1.02-5.38$ & 0.044 & 2.73 & $1.01-7.47$ & 0.050 \\
\hline $\begin{array}{l}\text { FLAIR-T } 2 \geq \\
2,000 \mathrm{~mm}^{2}\end{array}$ & 3.06 & $1.04-8.97$ & 0.041 & 3.52 & $1.11-11.2$ & 0.027 \\
\hline $\mathrm{FTR}^{\mathrm{a}} \geq 5$ & 0.97 & $0.41-2.34$ & 0.954 & 1.84 & $0.68-5.02$ & 0.229 \\
\hline
\end{tabular}

${ }^{a}$ FLAIR-T2/tumor ratio; HR, Hazard ratio; Cl, confidence interval.
FLAIR-T $T_{2}$ volume $\geq 60 \mathrm{~cm}^{3}$ by the semi-automatic method was associated with shorter OS, with median survival times of $13 \pm 1.8 \mathrm{~m}\left(\geq 60 \mathrm{~cm}^{3}\right)$ vs. $24 \pm 6.5 \mathrm{~m}\left(<60 \mathrm{~cm}^{3}\right)$, respectively (Figure 7B, HR $=2.84, p=0.024$ ). A similar impact was observed with the $3 \mathrm{D}$ ellipsoid method, with the median survival ranging from $15 \pm 1.8\left(\geq 60 \mathrm{~cm}^{3}\right)$ to $24 \pm 5.8 \mathrm{~m}(<60$ $\mathrm{cm}^{3}$ ), (Figure 7A, HR $=2.35, p=0.051$ ), reaching closely statistical significance. The FLAIR- $\mathrm{T}_{2}$ volume $\geq 60 \mathrm{~cm}^{3}$ had also impact in progression-free survival by both $3 \mathrm{D}$ methods (Figures 7C,D); FLAIR-T $T_{2}$ area $\geq 2,000 \mathrm{~mm}^{2}$ as determined by the $2 \mathrm{D}$ diameter method was also associated with shorter OS $(\mathrm{HR}=3.06, p=0.041)$.

Necrosis/Tumor ratio had no impact on survival $(p=0.798)$. The FLAIR-T $T_{2}$ tumor ratio by the semi-automatic method had a negative impact on survival $(p=0.008)$ without detecting such an association with the $3 \mathrm{D}$ ellipsoid and 2D diameter methods.

\section{Multivariate Analysis}

Finally, we implemented a multivariate analysis (Cox Regression analysis) strategy to identify the independent predictors of OS among the demographic, imaging, and genetic variables that were significant in the bivariate analysis. We carried out the analysis individualizing the results for each method (Tables 35). The following variables were involved; age $\geq 65$ years, MGMT methylation status, FLAIR-T 2 abnormality $\geq 60 \mathrm{~cm}^{3}$ or $\geq 2,000 \mathrm{~mm}^{3}$ and FLAIR-T $2 /$ tumor ratio $\geq 5$ for all methods.

TABLE 4 | Multivariate Cox Regression analysis with tumor volumetry as determined by the ellipsoid method.

\begin{tabular}{lcccccc}
\hline Variable & $\begin{array}{c}\text { Unadjusted } \\
\text { HR }\end{array}$ & $\mathbf{9 5 \%} \mathbf{C l}$ & $\boldsymbol{p}$-value & $\begin{array}{c}\text { Adjusted } \\
\text { HR }\end{array}$ & $\mathbf{9 5 \%} \mathbf{C l}$ & $\boldsymbol{p}$-value \\
\hline $\begin{array}{l}\text { Age } \geq 65 \\
\text { years }\end{array}$ & 2.76 & $1.30-5.84$ & 0.008 & 3.27 & $1.45-7.38$ & 0.004 \\
$\begin{array}{l}\text { MGMT } \\
\text { Unmethylated }\end{array}$ & 2.34 & $1.02-5.38$ & 0.044 & 2.25 & $0.98-5.43$ & 0.051 \\
$\begin{array}{l}\text { FLAIR-T } 2 \geq 60 \\
\text { cm }^{3}\end{array}$ & 2.35 & $0.95-5.84$ & 0.051 & 2.83 & $1.08-7.44$ & 0.034 \\
FTR $^{\mathrm{a}} \geq 5$ & 1.49 & $0.69-3.19$ & 0.302 & 1.43 & $0.64-3.19$ & 0.321
\end{tabular}

${ }^{a}$ FLAIR-T2/tumor ratio; HR, Hazard ratio; Cl, confidence interval.

TABLE 5 | Multivariate Cox Regression analysis with tumor volumetry as determined with the semi-automatic method.

\begin{tabular}{|c|c|c|c|c|c|c|}
\hline Variable & $\begin{array}{c}\text { Unadjusted } \\
\text { HR }\end{array}$ & $95 \% \mathrm{Cl}$ & $p$-value & $\begin{array}{l}\text { Adjusted } \\
\text { HR }\end{array}$ & $95 \% \mathrm{Cl}$ & $p$-value \\
\hline $\begin{array}{l}\text { Age } \geq 65 \\
\text { years }\end{array}$ & 2.76 & $1.30-5.84$ & 0.008 & 3.39 & $1.51-7.61$ & 0.003 \\
\hline $\begin{array}{l}\text { MGMT } \\
\text { Unmethylated }\end{array}$ & 2.34 & $1.02-5.38$ & 0.044 & 2.53 & $1.03-6.57$ & 0.046 \\
\hline $\begin{array}{l}\text { FLAIR-T } 2 \geq 60 \\
\mathrm{~cm}^{3}\end{array}$ & 2.84 & $1.07-7.55$ & 0.024 & 3.93 & $1.23-10.2$ & 0.018 \\
\hline $\mathrm{FTR}^{\mathrm{a}} \geq 5$ & 1.02 & $0.45-2.34$ & 0.956 & 1.62 & $0.62-4.18$ & 0.321 \\
\hline
\end{tabular}

${ }^{a}$ FLAIR-T2/tumor ratio; HR, Hazard ratio; Cl, confidence interval. 
The variable Hyperintensity in FLAIR- $\mathrm{T}_{2}$ involving the corpus callosum was excluded because did not provide more significance to the multivariate models due to the close association with the variable FLAIR-T $T_{2}$ volume $>60 \mathrm{~cm}^{3}$ (Fisher's exact test $p=$ 0.009). We found that independence of the variables FLAIR- $T_{2}$ $>60 \mathrm{~cm}^{3}$, age $>65$ years, as well as the MGMT methylation status, remained significant with a similar impact on OS than in the bivariate analysis.

\section{DISCUSSION}

Our pilot study investigates the prognostic value of three different methods of pre-surgical tumor size measurement by MRI, combined with relevant clinical and genetic information, as OS and PFS predictors. Briefly, we selected a homogeneous cohort of patients harboring primary glioblastomas (IDH wild type), who were candidates for resective surgery and adjuvant chemoradiotherapy. Tumor sizes and compartments were determined pre-operatively using the $2 \mathrm{D}$ diameter method recommended by the RANO $(23,24)$, the $3 \mathrm{D}$ ellipsoid formula $(25,26)$ and the semi-automatic 3D segmentation (33) methods. Clinical and genetic variables, including gender, age, expression of IDH mutation, and MGMT status, were investigated additionally.

In general, our results confirm the correlation of elderly patients with shorter OS, with the cut-off point in terms of survival prediction in 65 years, as well as the methylated status of the MGMT promoter with longer OS, two well-known variables normally associated with OS and PFS $(6,11)$. In addition, incomplete neurosurgical resections, considered as important negative survival markers $(4,38-40)$, depicted in the present study, only a trend to shorter OS without statistical significance, a finding probably related to the relatively small sample of the present patient cohort.

As far as pre-operative measurement of tumor size is concerned, the three methods employed in this study presented a high correlation $(41,42)$. Despite the semi-automatic segmentation method is currently considered the most accurate, because of its high adaptability to irregular morphologies, and the possibility to determine, separately, the different compartmental volumes $(27,43)$, its advantages in terms of prognosis over the $2 \mathrm{D}$ diameter and the 3D ellipsoid methods, did not reach statistical significance, even in measurements of tumor size in pre-operative images. This may be caused, at least in part, by the relatively homogeneous tumor morphology in the pre-operative period. However, post-surgical images show limits and contours much more difficult to be silhouetted, and consequently, the semiautomatic method is the only one that can provide insight of the actual volume of the post-surgical residual tumor volume.

Among the areas, volumes and ratios investigated, including necrosis, gadolinium enhancement in $\mathrm{T}_{1}$, tumor mass, necrosis/tumor, and FLAIR- $\mathrm{T}_{2} /$ tumor ratios, only FLAIR$\mathrm{T}_{2}$ hyper-intensity had an important impact in OS and PFS, with the three methods of tumor size measurement used. Hyper-intensity in FLAIR- $T_{2}$ surrounding tumor mass includes a mixture of peritumoral reactive edema and tumor cells with variable density, as has been previously characterized (44-46).
Present results confirm that, the higher the volume of the FLAIR- $T_{2}$ image, the worse the prognosis is. However, there is some controversy in this respect, since some studies have shown correlations between FLAIR- $\mathrm{T}_{2}$ hyper-intensities with longer OS $(13-18,40,47)$, while others have not been able to prove it $(12,13,48,49)$. Many factors, including the non-exclusion of cystic cavities, the influence of corticosteroid treatment, and the inclusion of both, IDH-mutated, and IDH wild-type tumors, may further underlie these discrepancies.

Additionally, some studies have reported associations with survival of the necrosis volume, enhancement tumor volume, and the tumor/necrosis ratio $(13,18,48)$. Our study could not confirm these, either in either bivariate or multivariate analyses. However, we observed a trend indicating that the volume of FLAIR-T $T_{2}$ hyper-intensity, tumor mass, and necrosis, were greater in the tumors with non-methylated MGMT promoter (50). The lower survival of this glioblastoma subgroup is clearly described by its greater resistance to alkylating chemotherapeutic agents, but it could also involve a higher rate of tumor growth, with higher volumes being observed in all measurements when diagnosing the disease, and before any treatment prescribed. Future studies with a larger sample size could contribute to clarify this finding.

Summarizing, our study shows that the size of FLAIR- $\mathrm{T}_{2}$ hyper-intensity, as measured by the three methods, presents a similar significant impact in the OS and PFS under both, bivariate and multivariate analyses. The larger the FLAIR- $\mathrm{T}_{2}$ hyper-intensity volume, the shorter OS and PFS predictions. On these basis, surgical resection of the largest part of the FLAIR$\mathrm{T}_{2}$ hyperintensity tissue might determine a better prognosis, in agreement with previous studies $(40,51,52)$. Additionally we show, that the $3 \mathrm{D}$ semi-automatic method, more complex and time consuming than the other alternatives $(22,53)$, ends up providing similar pre-operative tumor volumetry results, without any preponderance in terms of survival. Consequently, our study supports the use of the 2D diameter and 3D ellipsoid methods, to estimate FLAIR- $\mathrm{T}_{2}$ hyper-intensity areas and volumes, revealed here as parameters with an important impact in OS and PFS predictions.

\section{Limitations}

Acknowledged limitations of this pilot study relate to the single center implementation and the reduced size of the patient cohort. Thus, increasing the number of patients examined and extension to multicenter assays would constitute immediate priorities to validate the present observations.

\section{CONCLUSIONS}

The present study reveals that pre-operative tumor size estimations in primary glioblastoma, as determined by the $2 \mathrm{D}$ diameter and 3D ellipsoid methods, provide similar results to the 3D semi-automatic segmentation method. The three methods reveal that FLAIR- $\mathrm{T}_{2}$ hyperintensity areas and volumes, provide independent factors closely associated with OS and PFS predictions. The larger the FLAIR- $T_{2}$ hyper-intensity volume, the worse OS and PFS prediction. In addition, we emphasize the 
negative impact of age $\geq 65$ years and non-methylation of the MGMT promoter in survival predictions.

\section{DATA AVAILABILITY STATEMENT}

The raw data supporting the conclusions of this article will be made available by the authors, without undue reservation.

\section{ETHICS STATEMENT}

The studies involving human participants were reviewed and approved by Ethics Commitee University Hospital La Paz, Madrid. The patients/participants provided their written informed consent to participate in this study.

\section{AUTHOR CONTRIBUTIONS}

AP performed most of the surgeries, collected and integrated the patient data, applied the different volumetric methods to the image database, provided the univariate and multivariate statistical analyses, and wrote the first draft of the manuscript. $\mathrm{CV}$ collected and integrated the patient and imaging data, implemented the MRI volumetric methods, and contributed to

\section{REFERENCES}

1. Deorah S, Lynch CF, Sibenaller ZA, Ryken TC. Trends in brain cancer incidence and survival in the United States: surveillance, epidemiology, and end results program, 1973 to 2001. Neurosurg Focus. (2006) 20:E1. doi: $10.3171 /$ foc.2006.20.4.E1

2. Ostrom QT, Gittleman H, Fulop J, Liu M, Blanda R, Kromer C, et al. CBTRUS statistical report: primary brain and central nervous system tumors diagnosed in the United States in 2008-2012. Neuro Oncol. (2015) 17(Suppl 4):iv1-62. doi: 10.1093/neuonc/nov189

3. Hou LC, Veeravagu A, Hsu AR, Tse VCK. Recurrent glioblastoma multiforme: a review of natural history and management options. Neurosurg Focus. (2006) 20:E5. doi: 10.3171/foc.2006.20.4.2

4. Stupp R, Hegi ME, Mason WP, van den Bent MJ, Taphoorn MJB, Janzer RC, et al. Effects of radiotherapy with concomitant and adjuvant temozolomide versus radiotherapy alone on survival in glioblastoma in a randomised phase III study: 5-year analysis of the EORTC-NCIC trial. Lancet Oncol. (2009) 10:459-66. doi: 10.1016/S1470-2045(09)70025-7

5. Ohgaki $\mathrm{H}$, Kleihues $\mathrm{P}$. The definition of primary and secondary glioblastoma. Clin Cancer Res. (2013) 19:764-72. doi: 10.1158/1078-0432.CCR-12-3002

6. Louis DN, Perry A, Reifenberger G, von Deimling A, Figarella-Branger D, Cavenee WK, et al. The 2016 World Health Organization Classification of Tumors of the Central Nervous System: a summary. Acta Neuropathol. (2016) 131:803-20. doi: 10.1007/s00401-016-1545-1

7. Nobusawa S, Watanabe T, Kleihues P, Ohgaki H. IDH1 mutations as molecular signature and predictive factor of secondary glioblastomas. Clin Cancer Res. (2009) 15:6002-7. doi: 10.1158/1078-0432.CCR-09-0715

8. Esteller M, Garcia-Foncillas J, Andion E, Goodman SN, Hidalgo OF, Vanaclocha V, et al. Inactivation of the DNA-repair gene MGMT and the clinical response of gliomas to alkylating agents. N Engl J Med. (2000) 343:1350-4. doi: 10.1056/NEJM200011093431901

9. Hegi ME, Diserens A-C, Gorlia T, Hamou M-F, de Tribolet N, Weller M, et al. MGMT gene silencing and benefit from temozolomide in glioblastoma. NEngl J Med. (2005) 352:997-1003. doi: 10.1056/NEJMoa043331

10. Gandía-González ML, Cerdán S, Barrios L, López-Larrubia P, Feijoó PG, Palpan A Jr, et al. Assessment of overall survival in glioma the first draft of the manuscript. $\mathrm{AB}, \mathrm{CU}$, and $\mathrm{AR}$ contributed in the radiologic assessment of pre- and post-operative MRI and validated the volumetric measurements. MG performed many of the surgeries, validated demographic and histopathological assessments, and contributed to the final version of the manuscript. SC and JR integrated all clinical, neurosurgical, and imaging information and accomplished the writing of the final version, with all authors commenting. All authors contributed to the article and approved the submitted version.

\section{FUNDING}

This work was supported in part by grants PI 2017/00361 from Instituto de Salud Carlos III to JR, MG, and AP and by grant B2017/BMD3688 from the Community of Madrid to JR, MG, and SC.

\section{ACKNOWLEDGMENTS}

Authors wish to express their gratitude to the Neuroradiology and Pathology Departments of the Hospital La Paz, for professional handling of the MRI acquisitions and immunohistochemical determinations.

patients as predicted by metabolomic criteria. Front Oncol. (2019) 9:328. doi: 10.3389/fonc.2019.00328

11. Lacroix M, Abi-Said D, Fourney DR, Gokaslan ZL, Shi W, DeMonte F, et al. A multivariate analysis of 416 patients with glioblastoma multiforme: prognosis, extent of resection, and survival. J Neurosurg. (2001) 95:190-8. doi: 10.3171/jns.2001.95.2.0190

12. Iliadis G, Kotoula V, Chatzisotiriou A, Televantou D, Eleftheraki AG, Lambaki $\mathrm{S}$, et al. Volumetric and MGMT parameters in glioblastoma patients: survival analysis. BMC Cancer. (2012) 12:3. doi: 10.1186/1471-2407-12-3

13. Henker C, Kriesen T, Glass Ä, Schneider B, Piek J. Volumetric quantification of glioblastoma: experiences with different measurement techniques and impact on survival. J Neurooncol. (2017) 135:391-402. doi: 10.1007/s11060-017-2587-5

14. Hammoud MA, Sawaya R, Shi W, Thall PF, Leeds NE. Prognostic significance of preoperative MRI scans in glioblastoma multiforme. J Neurooncol. (1996) 27:65-73. doi: 10.1007/BF00146086

15. Pope WB, Sayre J, Perlina A, Villablanca JP, Mischel PS, Cloughesy TF. MR imaging correlates of survival in patients with high-grade gliomas. AJNR Am J Neuroradiol. (2005) 26:2466-74.

16. Li W-B, Tang K, Chen Q, Li S, Qiu X-G, Li S-W, et al. MRI manifestions correlate with survival of glioblastoma multiforme patients. Cancer Biol Med. (2012) 9:120-3. doi: 10.3969/j.issn.2095-3941.2012.02.007

17. Schoenegger K, Oberndorfer S, Wuschitz B, Struhal W, Hainfellner J, Prayer D, et al. Peritumoral edema on MRI at initial diagnosis: an independent prognostic factor for glioblastoma? Eur J Neurol. (2009) 16:8748. doi: 10.1111/j.1468-1331.2009.02613.x

18. Wu C-X, Lin G-S, Lin Z-X, Zhang J-D, Chen L, Liu S-Y, et al. Peritumoral edema on magnetic resonance imaging predicts a poor clinical outcome in malignant glioma. Oncol Lett. (2015) 10:2769-76. doi: 10.3892/ol.2015.3639

19. Pierallini A, Bonamini M, Osti MF, Pantano P, Palmeggiani F, Santoro A, et al. Supratentorial glioblastoma: neuroradiological findings and survival after surgery and radiotherapy. Neuroradiology. (1996) 38(Suppl 1):S26-30. doi: 10.1007/BF02278114

20. Macdonald DR, Cascino TL, Schold SC, Cairncross JG. Response criteria for phase II studies of supratentorial malignant glioma. J Clin Oncol. (1990) 8:1277-80. doi: 10.1200/JCO.1990.8.7.1277 
21. Wen PY, Macdonald DR, Reardon DA, Cloughesy TF, Sorensen AG, Galanis E, et al. Updated response assessment criteria for high-grade gliomas: response assessment in neuro-oncology working group. J Clin Oncol. (2010) 28:196372. doi: 10.1200/JCO.2009.26.3541

22. Dempsey MF, Condon BR, Hadley DM. Measurement of tumor "size" in recurrent malignant glioma: 1D, 2D, or 3D? AJNR Am J Neuroradiol. (2005) 26:770-6.

23. Wen PY, Chang SM, Van den Bent MJ, Vogelbaum MA, Macdonald DR, Lee EQ. Response assessment in neuro-oncology clinical trials. J Clin Oncol. (2017) 35:2439-49. doi: 10.1200/JCO.2017.72.7511

24. Ellingson BM, Wen PY, Cloughesy TF. Modified criteria for radiographic response assessment in glioblastoma clinical trials. Neurotherapeutics. (2017) 14:307-20. doi: 10.1007/s13311-016-0507-6

25. Opalak CF, Parry M, Rock AK, Sima AP, Carr MT, Chandra V, et al. Comparison of $\mathrm{ABC} / 2$ estimation and a volumetric computerized method for measurement of meningiomas using magnetic resonance imaging. $J$ Neurooncol. (2019) 144:275-82. doi: 10.1007/s11060-019-03205-Z

26. Leu S, Boulay J-L, Thommen S, Bucher HC, Stippich C, Mariani $\mathrm{L}$, et al. Preoperative two-dimensional size of glioblastoma is associated with patient survival. World Neurosurg. (2018) 115:e448-63. doi: 10.1016/j.wneu.2018.04.067

27. Sorensen AG, Patel S, Harmath C, Bridges S, Synnott J, Sievers A, et al. Comparison of diameter and perimeter methods for tumor volume calculation. J Clin Oncol. (2001) 19:551-7. doi: 10.1200/JCO.2001.19.2.551

28. Czarnek N, Clark K, Peters KB, Mazurowski MA. Algorithmic threedimensional analysis of tumor shape in MRI improves prognosis of survival in glioblastoma: a multi-institutional study. J Neurooncol. (2017) 132:55-62. doi: 10.1007/s11060-016-2359-7

29. Vandenbroucke JP, von Elm E, Altman DG, Gøtzsche PC, Mulrow CD, Pocock SJ, et al. Strengthening the reporting of observational studies in epidemiology (STROBE). Epidemiology. (2007) 18:805-35. doi: 10.1097/EDE.0b013e3181577511

30. Nabors LB, Portnow J, Ammirati M, Baehring J, Brem H, Butowski N, et al. NCCN guidelines insights: central nervous system cancers, version 1.2017. J Natl Compr Cancer Netw. (2017) 15:1331-45. doi: 10.6004/jnccn.20 17.0166

31. Henegar MM, Moran CJ, Silbergeld DL. Early postoperative magnetic resonance imaging following nonneoplastic cortical resection. J Neurosurg. (1996) 84:174-9. doi: 10.3171/jns.1996.84.2.0174

32. Stupp R, Brada M, van den Bent MJ, Tonn J-C, Pentheroudakis G. High-grade glioma: ESMO Clinical Practice Guidelines for diagnosis, treatment and follow-up. Ann Oncol. (2014) 25(suppl 3):iii93-101. doi: 10.1093/annonc/mdu050

33. Sreenivasan S, Madhugiri V, Sasidharan G, Kumar RR. Measuring glioma volumes: A comparison of linear measurement based formulae with the manual image segmentation technique. J Cancer Res Ther. (2016) 12:161. doi: 10.4103/0973-1482.153999

34. Setty P, Hammes J, Rothämel T, Vladimirova V, Kramm CM, Pietsch $\mathrm{T}$, et al. A pyrosequencing-based assay for the rapid detection of IDH1 mutations in clinical samples. J Mol Diagn. (2010) 12:750-6. doi: 10.2353/jmoldx.2010.090237

35. Eads CA, Danenberg KD, Kawakami K, Saltz LB, Blake C, Shibata D, et al. MethyLight: a high-throughput assay to measure DNA methylation. Nucleic Acids Res. (2000) 28:E32. doi: 10.1093/nar/28.8.e32

36. Sawaya R, Hammoud M, Schoppa D, Hess KR, Wu SZ, Shi W-M, et al. Neurosurgical outcomes in a modern series of 400 craniotomies for treatment of parenchymal tumors. Neurosurgery. (1998) 42:1044-55. doi: 10.1097/00006123-199805000-00054

37. Mor V, Laliberte L, Morris JN, Wiemann M. The Karnofsky performance status scale. An examination of its reliability and validity in a research setting. Cancer. (1984) 53:2002-7. doi: 10.1002/10970142(19840501)53:9<2002::AID-CNCR2820530933>3.0.CO;2-W

38. Sanai N, Polley M-Y, McDermott MW, Parsa AT, Berger MS. An extent of resection threshold for newly diagnosed glioblastomas. J Neurosurg. (2011) 115:3-8. doi: 10.3171/2011.2.JNS10998

39. Keles GE, Anderson B, Berger MS. The effect of extent of resection on time to tumor progression and survival in patients with glioblastoma multiforme of the cerebral hemisphere. Surg Neurol. (1999) 52:371-9. doi: 10.1016/S0090-3019(99)00103-2

40. Li YM, Suki D, Hess K, Sawaya R. The influence of maximum safe resection of glioblastoma on survival in 1229 patients: can we do better than gross-total resection? J Neurosurg. (2016) 124:977-88. doi: 10.3171/2015.5.JNS142087

41. Porz N, Bauer S, Pica A, Schucht P, Beck J, Verma RK, et al. Multi-modal glioblastoma segmentation: man versus machine. Strack S, editor. PLoS One. (2014) 9:e96873. doi: 10.1371/journal.pone.0096873

42. Chang K, Beers AL, Bai HX, Brown JM, Ly KI, Li X, et al. Automatic assessment of glioma burden: a deep learning algorithm for fully automated volumetric and bidimensional measurement. Neuro Oncol. (2019) 21:141222. doi: $10.1093 /$ neuonc/noz106

43. Gahrmann R, van den Bent M, van der Holt B, Vernhout RM, Taal W, Vos $\mathrm{M}$, et al. Comparison of 2D (RANO) and volumetric methods for assessment of recurrent glioblastoma treated with bevacizumab-a report from the BELOB trial. Neuro Oncol. (2017) 19:853-61. doi: 10.1093/neuonc/now311

44. Eidel O, Burth S, Neumann J-O, Kieslich PJ, Sahm F, Jungk C, et al. Tumor infiltration in enhancing and non-enhancing parts of glioblastoma: a correlation with histopathology. Kleinschnitz C, editor. PLoS One. (2017) 12:e0169292. doi: 10.1371/journal.pone.0169292

45. Tamura R, Ohara K, Sasaki H, Morimoto Y, Yoshida K, Toda M. Histopathological vascular investigation of the peritumoral brain zone of glioblastomas. J Neurooncol. (2018) 136:233-41. doi: $10.1007 /$ s11060-017-2648-9

46. Zinn PO, Mahajan B, Majadan B, Sathyan P, Singh SK, Majumder S, et al. Radiogenomic mapping of edema/cellular invasion MRI-phenotypes in glioblastoma multiforme. Deutsch E, editor. PLoS One. (2011) 6:e25451. doi: 10.1371/journal.pone.0025451

47. Ramnarayan R, Dodd S, Das K, Heidecke V, Rainov NG. Overall survival in patients with malignant glioma may be significantly longer with tumors located in deep grey matter. J Neurol Sci. (2007) 260:49-56. doi: 10.1016/j.jns.2007.04.003

48. Henker C, Hiepel MC, Kriesen T, Scherer M, Glass Ä, Herold-Mende C, et al. Volumetric assessment of glioblastoma and its predictive value for survival. Acta Neurochir (Wien). (2019) 161:1723-32. doi: 10.1007/s00701-019-03966-6

49. Gutman DA, Cooper LAD, Hwang SN, Holder CA, Gao J, Aurora TD, et al. MR Imaging predictors of molecular profile and survival: multi-institutional study of the TCGA glioblastoma data set. Radiology. (2013) 267:560-9. doi: 10.1148/radiol.13120118

50. Chahal M, Xu Y, Lesniak D, Graham K, Famulski K, Christensen JG, et al. MGMT modulates glioblastoma angiogenesis and response to the tyrosine kinase inhibitor sunitinib. Neuro Oncol. (2010) 12:822-33. doi: 10.1093/neuonc/noq017

51. Molinaro AM, Hervey-Jumper S, Morshed RA, Young J, Han SJ, Chunduru $\mathrm{P}$, et al. Association of maximal extent of resection of contrast-enhanced and non-contrast-enhanced tumor with survival within molecular subgroups of patients with newly diagnosed glioblastoma. JAMA Oncol. (2020) 6:495-503. doi: 10.1001/jamaoncol.2019.6143

52. Boxerman JL, Zhang Z, Safriel Y, Rogg JM, Wolf RL, Mohan S, et al. Prognostic value of contrast enhancement and FLAIR for survival in newly diagnosed glioblastoma treated with and without bevacizumab: results from ACRIN 6686. Neuro Oncol. (2018) 20:1400-10. doi: 10.1093/neuonc/noy049

53. Egger J, Kapur T, Fedorov A, Pieper S, Miller J V., Veeraraghavan H, et al. GBM volumetry using the 3D slicer medical image computing platform. Sci Rep. (2013) 3:1364. doi: 10.1038/srep01364

Conflict of Interest: The authors declare that the research was conducted in the absence of any commercial or financial relationships that could be construed as a potential conflict of interest.

Copyright $\odot 2020$ Palpan Flores, Vivancos Sanchez, Roda, Cerdán, Barrios, Utrilla, Royo and Gandía González. This is an open-access article distributed under the terms of the Creative Commons Attribution License (CC BY). The use, distribution or reproduction in other forums is permitted, provided the original author(s) and the copyright owner(s) are credited and that the original publication in this journal is cited, in accordance with accepted academic practice. No use, distribution or reproduction is permitted which does not comply with these terms. 